\title{
Parameter Estimation of Reverse Osmosis Process Model for Desalination
}

\author{
S. Sobana and Rames C. Panda*1 \\ *Sr. Scientist \& Faculty, Chemical Engineering Department, \\ CSIR-CLRI, Adyar, Chennai - 600020, India. \\ Tel: +91(44)24437115 Fax: +91(44)24911589 \\ Email: panda@clri.res.in \\ ${ }^{1}$ Corresponding author: Email - panda@clri.res.in; Fax - +91(44)24911589; DAAD fellow; Ex-Faculty, \\ Chemical Engineering Department, Curtin University of Technology, Perth, Australia.
}

\begin{abstract}
The present work pertains to modelling and identification of seawater desalination system using reverse osmosis. Initially the manipulated variable (feed pressure and recycle ratio) and the measured variables (flowrate, concentration and $\mathrm{pH}$ of permeate) are identified from reverse osmosis desalination system. The model of reverse osmosis was developed from the first principle approach using the mass balance equation (taking into consideration effect of concentration polarisation) from which the transfer function model was developed. The parameters of multi-input multi-output model are identified using the autoregressive exogenous linear identification technique. The states of the process model were also estimated using Kalman filter and parameters are identified by nonlinear least square (NNLS) algorithm. The plant's data of spiral wound model are given as input to all the identification methods. The results obtained from the predicted and the linear models are in good agreement with these obtained for the same plant data.
\end{abstract}

Keywords: desalination; modelling; identification; Kalman filter; nonlinear least square

\section{Academic Discipline And Sub-Disciplines}

Instrumentation Engineering : Chemical Engineering / Process Control

\section{SUBJECT CLASSIFICATION}

Estimation of Parameters

\section{TYPE (METHOD/APPROACH)}

Theoretical and Experimental analysis on reverse osmosis system

\section{Council for Innovative Research}

Peer Review Research Publishing System

Journal: INTERNATIONAL JOURNAL OF COMPUTERS \& TECHNOLOGY

Vol 11, No. 6

editor@cirworld.com

www.cirworld.com, member.cirworld.com 


\section{INTRODUCTION}

Water has become scarce as consumption has increased due to the increase in population and higher standards of living. $97.5 \%$ of the world's water resources are exited salt water in the ocean and seas in addition to brackish water. Desalination is a process to convert high total dissolved solid (TDS) sea water into low TDS portable water so that water can be used for the public. Other uses of desalination were waste water treatment, production of industrial grade water and de-watering of food stuffs. At present, a number of large desalination plants were operated by semi permeable membrane techniques (electro dialysis and reverse osmosis). Among these desalination methods, the reverse osmosis desalination method has the advantage from the point of view of low energy consumption. Modelling of reverse osmosis (RO) is necessary for scale up/down and optimization studies. Two types of models are available in literature for desalination process using RO. They are: mechanistic model (or) membrane transport model. Lumped parameter or mechanistic models consider the top thin skin of asymmetric membrane. Most of the transport membrane models assume equilibrium in the membrane diffusion process and describe steady state phenomena. This model is subdivided into three categories: irreversible thermodynamic model, nonporous (or) homogeneous model and pore model. A detailed review on modelling RO systems has been given by Sobana \& Panda (2011).

The lumped parameter models converge on steady as well as transient behaviour of the desalination process. After the model has been developed it is necessary to assess the accuracy of the obtained model. Alatiqi. et.al. (1989) used system identification techniques to estimate a MIMO structure of RO plant at Doha. Assef et.al (1995), Riveral and Pilipovic (2005) and Roberton.et.al (1996) also developed multivariable transfer function models from the plant input and output data where the model structure was obtained by fitting step response into second order transfer function with numerator zero. Zilouchion (2001) identified multivariable RO desalination photovoltaic process in the form of a transfer function matrix as well as state space representation by the recursive least square techniques Assef.et.al (1995) presented the model by step response data and fitting, where input and output were defined in a different way. Ramaswamy et al (1995) applied fully connected multilayer feed forward artificial neural network using the back propagation algorithm to identify the nonlinear multivariable multistage flash desalination plant. Both MISO and MIMO network have been used for the purpose of identification. Fkirin .et.al (1997) presented an optimal identification which was applied for the time varying dynamic process based on linear combination of the recursive least square method. This scheme was applied to identify the parameters and to predict the ARMAX model of online desalination process. Saengrug et.al (2005) modelled two reverse osmosis plants using system identification and ANN tools. Riverol and Pilipovic (2005) obtained the model by identification of a discrete time model in Z domain and back transformation to S domain. Senthil et. al. (2006) formulated a model for separating solutes from aqueous system using $\mathrm{RO}$ system with hollow fibres and using part of the experimental results for the binary and ternary system separation. Gambier et.al (2007) derived a lumped parameter dynamic MIMO model from first principle laws and used it for fault diagnosis purpose. Ahmed et.al (2007) developed and simulated a membrane transport model suitable for the multiple solutes systems in RO for unsteady state condition.Chaaben.et.al. (2008) developed a MIMO model by empirical transfer matrix for a small photovoltaic RO desalination process. Purkait et.al. (2009) presented experimental data and modelling for membrane based treatment leather plant effluent where the experimental flux data were correlated and analyzed by ANN. Sobana and Panda (2013) reported separate models for different subsections of a complete desalination plant and the integrated scheme was simulated. But all the above works leads to cumbersome methods and consume lot of computer time for solving. They do not give a picture to solve the system as an integral desalination plant. As the membrane diffusion process is nonlinear, states of the system needs to be estimated in order to understand transient profiles of the system.

The objective of this work is to identify parameters of the RO process model using ARX. Moreover, the model of the RO outputs (i.e) flowrate, concentration and $\mathrm{pH}$ of permeate stream was predicted using the NNLS and extended Kalman filter. The predicted results are compared from the model developed by the Laplace transformation. The rest of the paper is organized as follows. Section 2 discusses the process description. Section 3 discusses the mathematical modelling of the RO process. Section 4 discusses the identification of RO process using Autoregressive Exogenous (ARX), Kalman filter and NNLS methods. Section 5 discusses the result and discussion and conclusion is drawn in section 6 .

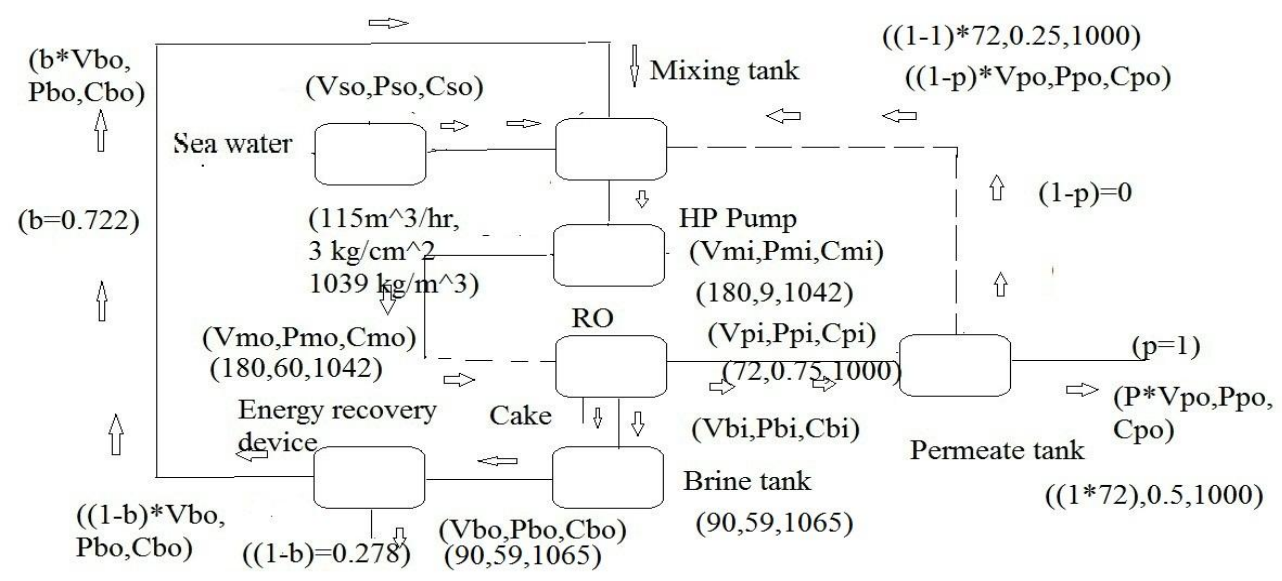

Figure 1. Process flow scheme of desalination plant with streams at operating condition 


\subsection{PROCESS DESCRIPTION}

Figure1 describes a simple schematic of a RO desalination process. Raw water is pre-treated and stored in an equalisation tank. The raw water is filtered by filter section consisting of three number of rough dual media filters (RDMT), three of polished dual media filters (PDMF), twelve no of cartridge filter and three number of disc filter. Raw water is pumped to the membrane module using the high pressure centrifugal pump to overcome osmotic pressure. Feed water is transformed into portable water using the high pressure developed by HP pump to overcome the osmotic pressure, when the feed water travelling in the RO bed. In this process the measured variables are the flow rate, concentration of the dissolved solids in the product water and the $\mathrm{pH}$ of the portable water. The manipulated variables are the pressure on feed water and the recycle ratio. The load is the flow rate of feed water as it varies according to the demand. Figure 2 shows the block diagram of RO module. The permeate comes out from the RO in the radial direction and the axial flow stream goes as rejection (or) brine. In order to estimate the parameters from input/output data, a model structure representing the $\mathrm{RO}$ process is necessary.

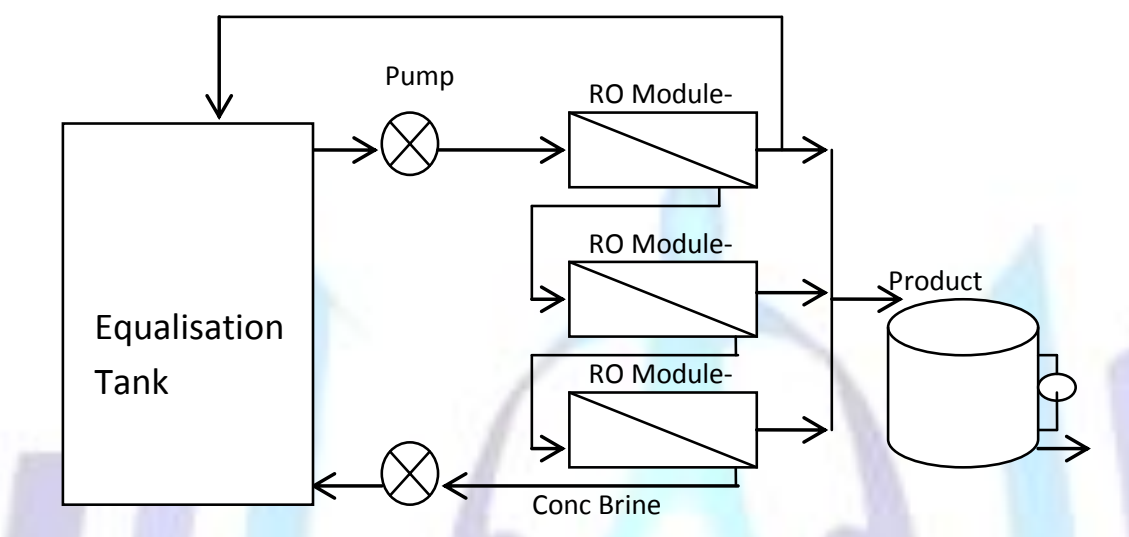

Figure 2. simple schematic of a RO desalination process

\subsection{Data collected across each unit of the Experimental setup}

The experiments were performed on the RO desalination process equipped with spiral membranes. The data for feed, brine and permeate flow rate, TDS, $\mathrm{pH}$ and the HP (high pressure) pump were collected across the mixing tank, brine tank, permeate tank and portable water tank for the verification of the dynamic and steady state operation of the mixing tank, brine tank, permeate tank, RO and portable tank during the starting of the process after the power shunt down of the plant for nearly15 minutes.

\subsection{MATHEMATICAL MODEL FOR RO PROCESS}

\section{- Feed/Equalization Tank}

The Laplace transformed transient mass balance equation around the mixing tank becomes

$$
C_{m T}(s)=\frac{F_{s o} C_{s o}(s)}{s V_{m T}+F_{m m}}+\frac{b F_{b o} C_{b o}(s)}{s V_{m T}+F_{m m}}+\frac{[1-p] F_{p o} C_{p o}(s)}{s V_{m T}+F_{m m}}
$$

Where, ' $s$ ' is Laplace variable

\section{- Membrane Module}

Fluid transport through the cylindrical porous membrane (of length $L$ and radius $R$ ) is assumed to have axial (ux (or) in horizontal) and radial (uy (or) in vertical) component of velocity. The radial component gives rise to permeate flow. The concentration polarisation developed due to separation of boundary layer is given by

$$
\frac{\partial C}{\partial t}=D_{L} \frac{\partial^{2} C}{\partial y^{2}}-u_{y} \frac{\partial C}{\partial y}-u_{x} \frac{\partial C}{\partial x}
$$

with initial conditions: $\mathrm{C}=0$ at $\mathrm{t}=0$

and boundary conditions: $\mathrm{C}=\mathrm{C} 0$ at $\mathrm{x}=0$,

$$
\begin{aligned}
& \frac{\partial C}{\partial y}=0 \quad \text { at } \quad y=0 \\
& D_{L} \frac{\partial C}{\partial y}=u_{y} C-V_{P} C_{P} \text { at } \mathrm{y}=\mathrm{R}
\end{aligned}
$$


The solution of the above equation has been achieved as

$$
C=\frac{2}{L} \sum_{n=1}^{\infty} \sin \left(\frac{n \pi y}{L}\right) \sin \left(\frac{n \pi x}{L}\right) e^{-\kappa^{2} D_{L} U t}
$$

$U=\sqrt{u_{x}^{2}+u_{y}^{2}} \quad u_{\text {and }}=\frac{\nabla}{2 \eta}$
Where
$\kappa^{2}=\frac{d y^{2}}{y}=\left(\frac{n \pi}{L}\right)^{2}=$ constant $(\approx 0.1,0.2, \ldots, 1.0)$

and $u_{x}=u_{m}\left(\frac{R^{2}-x^{2}}{R^{2}}\right)$

and

$$
\kappa^{2}=\frac{d y^{2}}{y}=\left(\frac{n \pi}{L}\right)^{2}=\text { constant }(\approx 0.1,0.2, \ldots, 1.0)
$$

um is the fluid velocity at centre of the membrane tube.

\section{- Brine Tank}

The Laplace transformation of the concentration dynamics in brine tank is given as

$$
C_{b T}(s)=\frac{F_{m m}}{s V_{b T}+F_{b o}} C_{m m}(s)-\frac{F_{p i}}{s V_{b T}+F_{b o}} C_{p i}(s)-\frac{F_{c o}}{s V_{b T}+F_{b o}} C_{c o}(s)
$$

\section{- Product Tank}

The stream coming out in radial direction gets accumulated in the product tank at a rate of Fp. A part of product water flow may be withdrawn (Fw) as per demand (or) it can be recirculated (p parts) to the feed tank. The Laplace transformation of a mass balance around the product tank is as follows.

$$
\frac{C_{p T^{(s)}}}{C_{p i}(s)}=\frac{F_{m m}-F_{b i}-F_{c o}}{s V_{p T}+\left(F_{m m}-F_{b i}-F_{c o}\right)}
$$

\section{pH Equation/Calculation}

$$
\mathrm{H}^{+}+\mathrm{H}_{2} \mathrm{O} \leftrightarrow \mathrm{H}_{3} \mathrm{O}^{+}
$$

The hydronium ion present in the water can be expressed as

$$
H_{3} O=\sqrt{K C_{a}}
$$

Where $\mathrm{K}$ is the dissociation constant of hydronium ions and $\mathrm{Ca}$ is their concentration. From the above expression the $\mathrm{pH}$ of the water is expressed as follows.

$$
p H=-\log \left[H_{3} O\right]
$$

Taking the Taylors approximation

$$
H=\log \left[\sqrt{K_{p e r}} * \sqrt{C_{P T s S}}+\left[\frac{\sqrt{K_{p e r}}}{2 * \sqrt{C_{P T s S}}}\left(C_{P T}-C_{P T s S}\right)\right]\right]
$$

Where CPTss is steady state permeate concentration of the permeate stream. This equation can be used to calculate $\mathrm{pH}$ of the permeate streams.

Eq (5) is basically a lumped equation representing the flow dynamics of permeate. These equations (1-8) are solved in MATLAB and the transient responses of flowrate, concentration and $\mathrm{pH}$ at the exit of $\mathrm{RO}$ module and the portable water tank and brine are obtained from step disturbance in feed streams of respective units. 


\subsection{IDENTIFICATION}

The RO system was modelled as two inputs and three outputs MIMO with FOPDT components. The generalised transfer function of the developed model for the MIMO- RO desalination plant for two inputs and three outputs using process reaction curve method are as follows.

$$
\left[\begin{array}{l}
Q_{P} \\
C_{P} \\
p H
\end{array}\right]=\left[\begin{array}{cc}
\frac{K_{P 11} e^{-D_{p 11} s}}{\tau_{P 11} s+1} & \frac{K_{P 12} e^{-D_{p 12} s}}{\tau_{P 12} s+1} \\
\frac{K_{P 21} e^{-D_{p 21} s}}{\tau_{P 22} s+1} & \frac{K_{P 22} e^{-D_{p 22} s}}{\tau_{P 22} s+1} \\
\frac{K_{P 31} e^{-D_{p 31} s}}{\tau_{P 31} s+1} & \frac{K_{P 32} e^{-D_{p 32} s}}{\tau_{P 32} s+1}
\end{array}\right]\left[\begin{array}{l}
\Delta P \\
R_{F B}
\end{array}\right]
$$

The inputs to the multivariable system are pump pressure $(\square \mathrm{P})$ and ratio (RFB) of flow rates of sea water feed to that of brine stream as it enters the equalization tank (as shown in Figure 1). The outputs to the multi input multi output system are permeate concentration, permeate flowrate and permeate $\mathrm{pH}$. The parameters to be identified from the model are $\mathrm{Kp}$, тр and $\mathrm{Dp}$. The equivalent $Z$ domain model of FOPDT is as follows. The transfer function of the developed model is as shown below.

$$
\left[\begin{array}{l}
F_{p} \\
C_{p} \\
p H_{p}
\end{array}\right]=\left[\begin{array}{l}
\frac{1.4944 e^{-0.55 s}}{0.71615 s+1} \\
\frac{-0.51 e^{-0.55 s}}{0.717834 s+1} \\
\frac{0.114411 e^{-0.55 s}}{7 s+1}
\end{array}\right.
$$

$\left.\begin{array}{c}\frac{0.092857 e^{-0.3666 s}}{1.1875 s+1} \\ \frac{-16.0482 e^{-0.2333 s}}{3.31 s+1} \\ \frac{0.178 e^{-0.15 s}}{2.5 s+1}\end{array}\right]\left[\begin{array}{l}\Delta P \\ R_{F B}\end{array}\right]$

The ARX identification technique is used to identify the parameters of RO desalination MIMO process as described in Eqn (10). The laplace model of feedtank, brine tank, permeate tank and the PDE equation for RO modules are used for EKF and NNLS identification techniques to identify the steady state model of RO and the parameters of the models.

$\frac{y(z)}{U(z)}=\frac{b_{1} Z^{-(l-1)}}{1-a_{1} z^{-1}}$

The parameters to be identified from the Z-domain are a1, b1 and I. The parameters of the S domain FOPDT can be retrieved/identified from the Z-domain FOPDT. (Ogata, 1987). They are as follows

$\mathrm{Kp}=\mathrm{b} 1 /(1-\mathrm{a} 1)$

$\mathrm{Tp}=(-\mathrm{ts} / \ln (\mathrm{a} 1))$

and, $\mathrm{Dp}=\mathrm{nk}$ *ts

(14)

where, ts is sampling time and $\mathrm{nk}$ is the dead time. The parameters $\mathrm{a} 1$ and $\mathrm{b} 1$ of $\mathrm{ARX}$ model are obtained from plant input/output data. The identification method for the ARX model is the least square method, which is a special case of the prediction error method. The least square is the most efficient polynomial estimation method that solves linear regression equation in analytic form. The solution is unique and is preferable especially when the model order is high. The general ARX model structure for the nth order is as follows

$$
y(k)+a_{1} y(k-1)+a_{n a} y(k-n a)=b_{1} u(k-n k)+\ldots . . b_{n b} u(k-n b-n k+1)+e(k)
$$

Where

na- is equal to the number of poles

$\mathrm{nb}$ - is the number of zeros

$\mathrm{nk}$ is the pure time-delay

For a system under sampled-data control, typically $\mathrm{nk}$ is equal to 1 if there is no dead-time. The structure for the first order ARX model is as follows 
$y(k)=-a_{1} y(k-1)+b_{1} u(k-1)$

$\theta=\left[a_{1} b_{1}\right]$ and $\phi(k)=[y(k-1) u(k-1)]$

This model can be rewritten as

$y=\phi \theta$

$\hat{\theta}=\left(\left(\phi \phi^{T}\right)^{-1}\right) \phi Y$

\subsection{Extended Kalman Filter:}

Due to concentration polarisation, the membrane diffusion equations become nonlinear in nature. Practical systems having nonlinear state equations can be estimated using Kalman filter technique. Updating or measurement of states using Kalman algorithm provides a way to design EKF algorithm that adapt multivariable Taylor series expansion to linearize the states and measurement equations about the predicted states as operating point. It allows numerical checking of Jacobian function. In EKF the state transition and observation models are differential function.

$x_{k}=f\left(x_{k-1,} u_{k-1}\right)+w_{k-1}$

$z_{k}=h\left(x_{k}\right)+v_{k}$

Where $w k=$ Process noise

vk=Observation noise $x_{k}=\left[\begin{array}{lll}C_{P} & F_{P} & p H\end{array}\right]^{T}, \quad u_{k}=\left[\begin{array}{ll}\Delta P & r\end{array}\right]$ with $r=\frac{F_{s}}{F_{s}+F_{b}}$ and $\mathrm{z}$ is measurement.

Both are assumed to have zero mean. The function f representing the nonlinear RO model equations, can be used to compute the predicted state from the previous estimate and similarly the output function $\mathrm{h}$ can be used to compute the predicted measurement from the predicted state. $\mathrm{f}$ and $\mathrm{h}$ can be computed by partial derivatives (Jacobian) and applied to the covariance. At each step the Jacobian is calculated with predicted state. This method uses linearized the nonlinear function around the current estimate. Continuous time extend Kalman filter model are as follows

\section{Prediction}

$x(\dot{t})=f(x(t), u(t))+w(t), w(t) \approx N(0, Q(t))$

$Z(t)=h(x(t))+v(t), v(t) \approx N(0, R(t))$

Initialization

$\hat{x}\left(t_{0}\right)=E\left[x\left(t_{0}\right)\right], p\left(t_{0}\right)=\operatorname{var}\left[x\left(t_{0}\right)\right]$

\section{Predict Update}

$$
x(\dot{t})=f(\hat{x}(t), u(t)+k(t)(z(t)-h(\hat{x}(t)))
$$

$\dot{P}(t)=F(t) P(t)+P(t) F(t)^{T}-K(t) H(t) P(t)+Q(t)$

$K(t)=P(t) H(t)^{T} R(t)^{-1}$

$F(t)=\frac{\partial f}{\partial x} \mid \hat{x}(t), u(t)$ 
$H(t)=\frac{\partial h}{\partial x} \mid \hat{x}(t)$

In the present case, there are three states (flowrate, concentration and $\mathrm{pH}$ ) involved and hence Eqn (25) having $\mathrm{x}$ as state variable will have three components/vectors. The measured output $z$ (Eqn. 23) also has three vectors. From the above model the estimation algorithm (Appendix-1) for extended Kalman filter model has been developed for the RO model.

\subsection{NonLinear Least square}

The aim of this method is to approximate the model as linear model and to refine the parameter by successive iteration

The structure of NLLS model is as follows

$Y=f(X, \beta)$

$Y$ is not only depend on $X$ but in addition it depend on the variable $\beta=(\beta 1 \beta 2 \ldots . . \beta n)$

The vector $\beta$ were found so that the curve fit best for the given data's in the least square sense, so that the sum of the square becomes minimum.

$$
S=\sum_{i=1}^{m} \gamma_{i}^{2} \text { is to be minimum }
$$

The residual (error) $\mathrm{yi}=\mathrm{Yi}-\mathrm{f}(\mathrm{Xi}, \beta)$

The minimum value of $S$ occurs when the gradient is zero. The model consists of $n$ parameters and so there are $n$ gradient equations. From the above NNLS model the following model has been developed for NNLS model for RO system

$$
Y=\frac{\mu X}{P_{0}+X+\frac{X^{2}}{P_{1}}}
$$

Where

$\mathrm{X}$ is the independent variables, for the $\mathrm{RO}$ system the independent parameters are feed pressure and recycle ratio. $\mathrm{Y}$ is the dependent variables which is permeate flow rate permeate concentration and permeate $\mathrm{pH}$. From the above NLLS model the following model has been developed for NLLS model for flux through RO system

$$
J_{W}=\frac{\Delta P-\Delta \pi}{\mu\left(R_{m}+R_{C}\right)}
$$

Where

$\Delta \mathrm{P}$ is the independent variables, for the RO system the independent parameters are feed pressure and recycle ratio. JW is the dependent variable. The parameters to be identified are $P=[R m, R C]$. The parameter to be identified from the permeate concentration model (4) is $P=[D, u m]$, diffusion constant and the fluid velocity at the centre of the membrane tube. The parameters to be identified for the permeate $\mathrm{pH}$ model (8) is $\mathrm{P}=[\operatorname{sqrt}($ Kper $)]$

Kper=dissociation constant of permeate concentration

\subsection{RESULTS and DISCUSSION}

Using the above model and using the equation (1-7) the graphical model for RO output response were predicted. The prediction matched well with the experimental model. 
Table 1 The normal operating conditions of the Plant

\begin{tabular}{|c|c|c|}
\hline $\begin{array}{l}\text { Serial } \\
\text { No }\end{array}$ & Variables & Value \\
\hline 1. & Concentration of feed in the mixing tank & $40000 \mathrm{ppm}$ \\
\hline 2. & Concentration of feed to $\mathrm{RO}$ module & 41350ppm \\
\hline 3. & Flowrate of feed to RO module & $180 \mathrm{~m} 3 / \mathrm{hr}$ \\
\hline 4. & Volume of feed water & $4.4944 \mathrm{~m} 3$ \\
\hline 5. & Flow rate of mixed feed water & $180 \mathrm{~m} 3 / \mathrm{hr}$ \\
\hline 6. & $\begin{array}{l}\text { Permeate (due to vertical component of velocity) comes out } \\
\text { along the surface of the membrane. The value is } 1 \text { if the } \\
\text { permeate is recycled }\end{array}$ & 0 \\
\hline 7. & $\begin{array}{l}\text { Concentrated brine (due to horizontal component of velocity) } \\
\text { flows axially through the membrane. The value is } 1 \text { if the } \\
\text { brine is recycled }\end{array}$ & 0.725 \\
\hline 8. & Concentration of permeate from the $\mathrm{RO}$ module & 850ppm \\
\hline 9. & Flow rate of permeate from the $\mathrm{RO}$ module & $80 \mathrm{~m} 3 / \mathrm{hr}$ \\
\hline 10. & Concentration of brine from the $\mathrm{RO}$ module & 60000ppm \\
\hline 11. & Flow rate of brine from the $\mathrm{RO}$ module & $90 \mathrm{~m} 3 / \mathrm{hr}$ \\
\hline
\end{tabular}

Table 1 shows the normal operating condition of the Plant. These conditions are used to simulate identified models. There are mixing tank, $\mathrm{RO}$ and brine tank sections in the present desalination process. $\mathrm{RO}$ section is the main component in desalination system. The desalination plant is considered to have two inputs $(\Delta \mathrm{P}$ and $\mathrm{r})$ and three outputs $(\mathrm{Cp}, \mathrm{Fp}$ and $\mathrm{pH})$ that are related by six component transfer functions. i.e., first input is related to three outputs by three transfer functions; similarly, second input is related to three outputs by other three transfer functions. Table 2 shows the identified component transfer functions of multi-

Table 2. Identified transfer function components in FOPDT structure for experimental, Simulation and ARX model

\begin{tabular}{|l|l|l|l|}
\hline S. No & Experimental Model & First Principle Model & ARX Model \\
\hline 1 & $\frac{P f(s)}{\Delta P(s)}=\frac{1.5364 e^{-0.45 s}}{0.753 s+1}$ & $\frac{P f(s)}{\Delta P(s)}=\frac{1.4944 e^{-0.55 s}}{0.716153 s+1}$ & $\frac{P f(s)}{\Delta P(s)}=\frac{1.5029 e^{-0.56 s}}{0.1955 s+1}$ \\
\hline 2 & $\frac{P c(s)}{\Delta P(s)}=\frac{-0.76 e^{-0.435 s}}{0.9834 s+1}$ & $\frac{P c(s)}{\Delta P(s)}=\frac{-0.51 e^{-0.55 s}}{0.717834 s+1}$ & $\frac{P c(s)}{\Delta P(s)}=\frac{-0.51 e^{-0.5743 s}}{0.128 s+1}$ \\
\hline 3 & $\frac{P p H(s)}{\Delta P(s)}=\frac{0.367 e^{-0.35 s}}{6.5 s+1}$ & $\frac{P p H(s)}{\Delta P(s)}=\frac{0.114411 e^{-0.55 s}}{7 s+1}$ & $\frac{P p H(s)}{\Delta P(s)}=\frac{0.1565 e^{-0.55 s}}{12.0855 s+1}$ \\
\hline 5 & $\frac{P f(s)}{R R(s)}=\frac{0.09867 e^{-0.326 s}}{1.1641 s+1}$ & $\frac{P f(s)}{R R(s)}=\frac{0.092857 e^{-0.3666 s}}{1.1875 s+1}$ & $\frac{P f(s)}{R R(s)}=\frac{0.0997 e^{-0.3555 s}}{1.2602 s+1}$ \\
\hline 6 & $\frac{P c(s)}{R R(s)}=\frac{-16.132 e^{-0.153 s}}{2.51 s+1}$ & $\frac{P c(s)}{R R(s)}=\frac{-16.0482 e^{-0.233 s}}{3.31 s+1}$ & $\frac{P c(s)}{R R(s)}=\frac{-18.4373 e^{-0.233 s}}{2.3997 s+1}$ \\
\hline
\end{tabular}

input-multi-output RO model in FOPDT structure from (i) experimental (reaction curve method) or transfer function, (ii) Least square model and the corresponding identified (iii) ARX model using input/output values from plant. In FOPDT structure, there are three unknown parameters, namely, process gain, time constant and dead time. The values of the identified parameters like Kp, Dp and тр (in all the six component transfer functions) are almost similar in all the three methods of identification. It is needed to validate these models with experimental values. These models are used to obtain three outputs (concentration, flow rate and $\mathrm{pH}$ of permeate) for changes in either of inputs (feed pressure and feed to 
recycle ratio). Step responses are obtained using experimental transfer functions (obtained by reaction curve method) as well as by using models obtained through extended Kalman filter (EKF) states. Figure 3 (1st column) gives the graphical output of responses from experimental model for step change of $10 \%$ in input feed pressure. Step changes on feed pressure are given and the responses are obtained using experiment (in real plant), theoretical models (transfer function model). These responses are permeate flow rate $(\mathrm{m} 3 / \mathrm{s})$, permeate concentration $(\mathrm{ppm})$ and permeate $\mathrm{pH}$ for the changes in feed pressure. In column 2 of Figure 3, both experimental and theoretical responses (from transfer function) are plotted. It can be seen that the experimental graphical model matches with the prediction model very well. Steady state estimates of permeate flowrate, concentration and $\mathrm{pH}$ are plotted in column 3 of Figure 3.

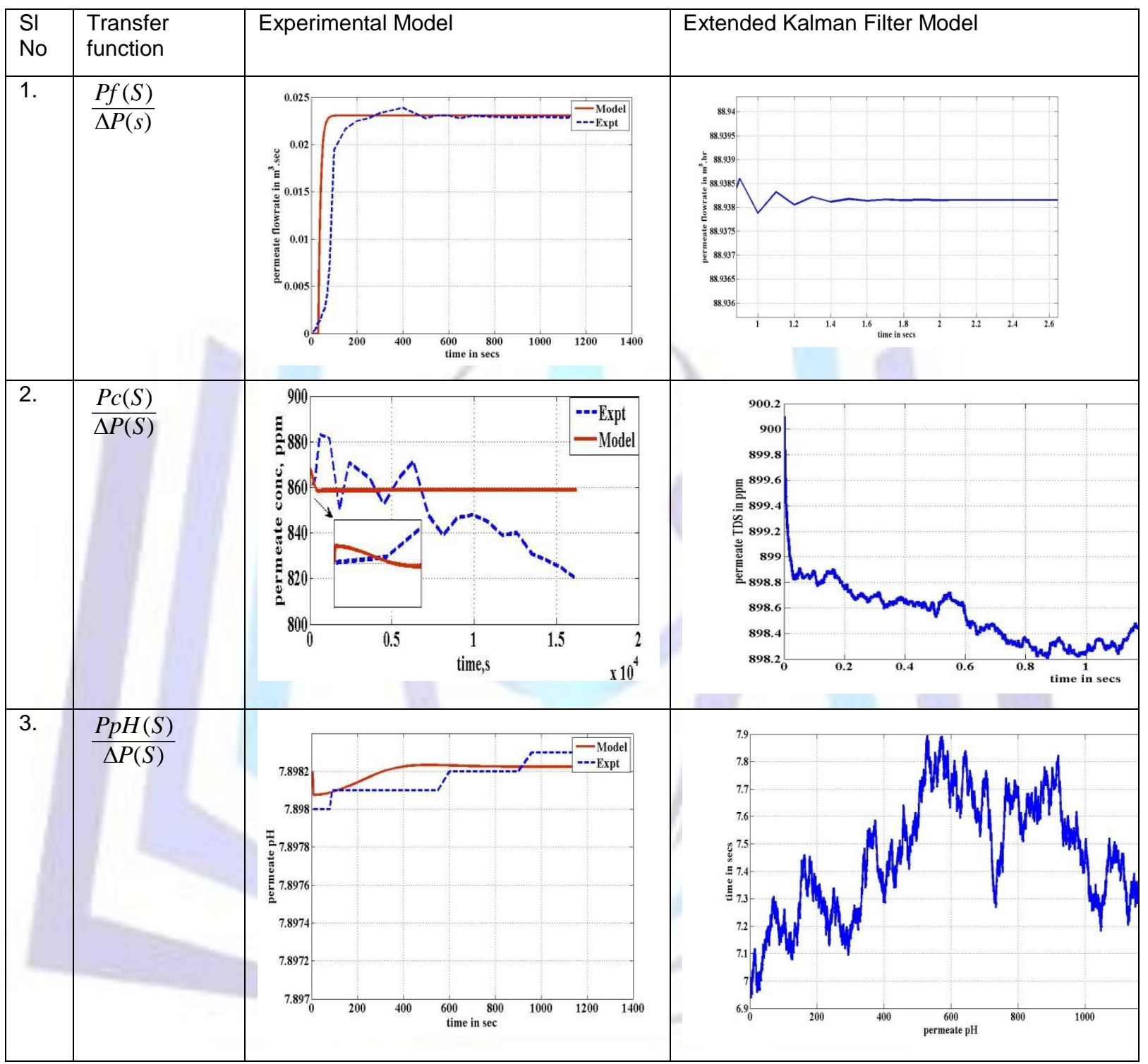

Figure 3. Comparison of responses obtained using (i) experimental model and the (ii) first principle model with parameters estimated using Kalman Filter

It can be observed that the responses obtained using EKF are smooth. Table 3 gives values for the parameters of estimation algorithm such as P0, P1 and the residuals for the RO MIMO system using NLLS techniques. It gives very low values of the residue, interpreting that the difference between the output and the predicted output is very less. Thus the present predicted model is in close adherence to actual plant. Based on this study, it is thought that the desalination process model with the Kalman filter algorithm can be extended for various control strategies and fault detection in the system 
Table 3 Values of variables and values of residuals of the MIMO transfer function

\begin{tabular}{|c|c|c|c|c|c|}
\hline \multirow{2}{*}{$\begin{array}{l}\text { Transfer } \\
\text { Function }\end{array}$} & \multicolumn{2}{|l|}{ Actual Value } & \multicolumn{2}{|l|}{ Calculated Value } & \multirow[t]{2}{*}{ Residual } \\
\hline & $\begin{array}{l}\text { Rm (Membrane } \\
\text { Resistance) } \\
\mathrm{m}-1\end{array}$ & $\begin{array}{l}\mathrm{Rc} \\
\text { (Cake } \\
\text { resistance) m- } \\
1\end{array}$ & $\mathrm{Rm}(\mathrm{m}-1)$ & $\mathrm{Rc}(\mathrm{m}-1)$ & \\
\hline \multirow{2}{*}{$\frac{P f(S)}{\Delta P(s)}$} & $96 * 104$ & $90 * 104$ & $95.99 * 104$ & $89.99 * 104$ & 0.3794 \\
\hline & $\begin{array}{l}\text { Diffusion } \\
\text { Constant } \\
\text { (m2/sec) }\end{array}$ & $\begin{array}{l}\text { Velocity of } \\
\text { flow } \\
(\mathrm{m} / \mathrm{sec})\end{array}$ & $\begin{array}{l}\text { Diffusion Constant } \\
\text { (m2/sec) }\end{array}$ & $\begin{array}{l}\text { Velocity of flow } \\
(\mathrm{m} / \mathrm{sec})\end{array}$ & \\
\hline \multirow{2}{*}{$\frac{P c(S)}{\Delta P(S)}$} & 0.9 & 0.562 & 0.8332 & 0.442 & 0.0856 \\
\hline & \multicolumn{2}{|l|}{ Kper } & \multicolumn{2}{|l|}{ Kper } & \\
\hline \multirow{2}{*}{$\frac{P p H(S)}{\Delta P(S)}$} & \multicolumn{2}{|l|}{$3.38 * 10-3$} & \multicolumn{2}{|l|}{0.0034} & 0 \\
\hline & $\mathrm{Rm}$ & $\mathrm{Rc}$ & $\mathrm{Rm}$ & $\mathrm{Rc}$ & \\
\hline \multirow{2}{*}{$\frac{P f(S)}{R R(S)}$} & $1.03^{*} 1011$ & $9 * 1011$ & $0.95^{\star} 1011$ & $8.98 * 1011$ & 2.0566 \\
\hline & \multicolumn{2}{|l|}{ Diffusion Constant } & \multicolumn{2}{|l|}{ Diffusion Constant } & \\
\hline \multirow{3}{*}{$\frac{P c(S)}{R R(s)}$} & \multirow{2}{*}{\multicolumn{2}{|c|}{2.8}} & \multirow[t]{2}{*}{2.6} & & \multirow[t]{2}{*}{0.2} \\
\hline & & & & & \\
\hline & \multicolumn{2}{|l|}{ Kper } & \multicolumn{2}{|l|}{ Kper } & \\
\hline$\frac{\operatorname{PpH}(S)}{R R(S)}$ & \multicolumn{2}{|l|}{$1.5127^{*} 10-6$} & \multicolumn{2}{|l|}{$1.5127^{*} 10-6$} & 0 \\
\hline
\end{tabular}

\subsection{CONCLUSION}

Desalination using reverse osmosis is one of the methods to produce portable drinking water and water for reuse for different purpose. This work considers a mixing tank, reverse osmosis membranes and brine storage tanks for modelling and efficient production of permeate. Mathematical models are necessary to study scale-up of design for the commercial exploitation of this technology. Nonsquare laplace transfer function models are identified

Table 4. Comparison of the multiplicative error between (i) experimental step response and validated model (from first principle); and (ii) experimental step response and ARX model

\begin{tabular}{|l|l|l|l|}
\hline Serial NO & Transfer Function & $\begin{array}{l}\text { Experimental and first } \\
\text { principle Model }\end{array}$ & $\begin{array}{l}\text { Experimental and ARX } \\
\text { model }\end{array}$ \\
\hline 1. & $\frac{P f(S)}{\Delta P(s)}$ & 8.2718 & 15.0611 \\
\hline 2. & $\frac{P c(S)}{\Delta P(S)}$ & 11.0061 & 15.5847 \\
\hline 3. & $\frac{P p H(S)}{\Delta P(S)}$ & 10.8502 & 14.5636 \\
\hline 4. & $\frac{P f(S)}{R R(s)}$ & 0.0589 & 0.0104 \\
\hline
\end{tabular}




\begin{tabular}{|l|l|l|l|}
\hline 5. & $\frac{P c(S)}{R R(S)}$ & 0.0052 & 0.1429 \\
\hline 6. & $\frac{P p H(S)}{R R(S)}$ & 0.3414 & 0.4981 \\
\hline
\end{tabular}

using (i) reaction curve (experimental) (ii) least square methods (iii) ARX with the FOPDT structure using actual plant input-output data (as given in Table 3). The multivariable transfer function that relates two inputs (feed pressure and feed to recycle ratio) and three outputs (concentration, flow rate and $\mathrm{pH}$ of permeate) have been validated using results on perturbation on input /feed pressure. Extended Kalman filter has been used to estimate / predict states of the system and it has been found that the prediction algorithm efficiently and accurately produces outputs with very less error. Outputs from reaction curve models are compared with that from experimental data to validate the model (Table 4). Outputs from EKF model are seen to be smoother. The mathematical model formulated here is used for synthesis of model based control law in future closed loop control system.

\section{Nomenclature}

$\mathrm{b}=\%$ of brine recycled to mixing tank taken from the brine tank (25)

$\mathrm{Cb}=$ Density of brine in $\mathrm{kg} / \mathrm{m3}=1064$

$\mathrm{Cbi}=$ Concentration of brine at the inlet of the brine tank in $\mathrm{mg} / \mathrm{ml}$

$\mathrm{Cbo}=$ Concentration of brine at the outlet of the brine tank in $\mathrm{mg} / \mathrm{ml}$

$C_{b o}=$ Concentration of brine recycle stream to mixing tank in $\mathrm{mg} / \mathrm{ml}$

$\mathrm{CbT}=$ Concentration of brine in brine tank in $\mathrm{mg} / \mathrm{ml}$

$\mathrm{Cc}=$ Concentration of brine from the $\mathrm{RO}$ module in $\mathrm{mg} / \mathrm{ml}$

Cci $=$ Concentration of cake in $\mathrm{mg} / \mathrm{ml}$

$\mathrm{Cf}=$ Feed water concentration in $\mathrm{mg} / \mathrm{ml}$

$\mathrm{Cmm}=$ Concentration of the exit stream from mixing tank entering into the membrane module.

$\mathrm{CmT}=$ Concentration of feed in the equalisation tank in $\mathrm{mg} / \mathrm{ml}$

$\mathrm{Cp}=$ Concentration of permeate from the $\mathrm{RO}$ module in $\mathrm{mg} / \mathrm{ml}$

Cpi $=$ Concentration of permeate inflow to the permeate tank in $\mathrm{mg} / \mathrm{ml}$

$\mathrm{CpT}=$ Concentration of permeate in the permeate tank in $\mathrm{mg} / \mathrm{ml}$

Cs = Saturation constant $=0.369 \mathrm{~kg} / \mathrm{m} 3$

Cso $=$ Concentration of sea water entering into the mixing tank in $\mathrm{mg} / \mathrm{ml}$

$C_{p o}=$ Concentration of permeate recycle to mixing tank, $\mathrm{mg} / \mathrm{ml}$

$\mathrm{Cw}=$ Concentration of Portable water in $\mathrm{mg} / \mathrm{ml}$

$\mathrm{Kw}=$ water mass transfer coefficient, $\mathrm{m} 2 / \mathrm{s}$

$\mathrm{p}=\%$ Permeate (due to vertical component of velocity) comes out along the surface of the membrane the value is 1 if the permeate is recycled $(=40 \%)$

$\mathrm{Pb}=$ Brine pressure, $\mathrm{kg} / \mathrm{m} 2$

$\mathrm{Pf}=$ Feed water pressure, $\mathrm{kg} / \mathrm{m} 2$

$\mathrm{Pp}=$ Permeate pressure, $\mathrm{kg} / \mathrm{m} 2$

$\mathrm{Fb}=$ Brine flow rate in $\mathrm{m} 3 / \mathrm{hr}$

$\mathrm{Fc}=$ Flow rate of brine from the $\mathrm{RO}$ module in $\mathrm{m} 3 / \mathrm{hr}$

$\mathrm{Ff}=$ Feed water flow rate in $\mathrm{m} 3 / \mathrm{hr}$

$\mathrm{Fmm}=$ Flow rate of permeate from the RO Module in $\mathrm{m} 3 / \mathrm{hr}$

$\mathrm{Fw}=$ Flow rate of portable water in $\mathrm{m} 3 / \mathrm{hr}$

$r=$ Concentrated brine (due to horizontal component of velocity) flows axially through the membrane, the value is 1 if the brine is recycled 
$R b t=$ resistance of the valve in the brine tank (for liner valve $R b t=1$ )

$\mathrm{Rc}=$ Resistance of the cake in the membrane, Pa.s.m-1

$\mathrm{Rm}=$ Resistance of membrane, Pa.s.m-1

$\mathrm{Rmr}=$ Resistance of the exit valve from mixing tank (for linear valve $\mathrm{Rmt}=1$ )

$R p t=$ Resistance of the exit valve from permeate tank (for linear valve $R p t=1$ )

Fbo $=$ Volumetric flow rate of brine output from brine tank in $\mathrm{m} 3 / \mathrm{hr}$

$\mathrm{VbT}=$ Volume of brine tank in $\mathrm{m} 3$

$\mathrm{Fci}=$ Volumetric flowrate of cake in $\mathrm{m} 3 / \mathrm{hr}$

Fco $=$ Volumetric flowrate of the cake in $\mathrm{m} 3 / \mathrm{hr}$

$\mathrm{Fmm}=$ Volumetric flow rate of mixing tank water entering the $\mathrm{RO}$ module in $\mathrm{m} 3 / \mathrm{hr}$

$\mathrm{VmT}=$ Volume of mixing tank in $\mathrm{m} 3$

$\mathrm{Fpi}=$ Volumetric flowrate of the inlet stream to the permeate tank

Fpo $=$ Volumetric flow rate of permeate from the output of the permeate tank in $\mathrm{m} 3 / \mathrm{hr}$

$\mathrm{VpT}=$ Volume of permeate tank in $\mathrm{m} 3$

Fso $=$ Volumetric flow rate of sea water to the mixing tank in $\mathrm{m} 3 / \mathrm{hr}$

\section{Suffix and prefix}

$\mathrm{b}=$ brine

$\mathrm{c}=$ cake

$f=$ feed

$\mathrm{i}=$ interface or inlet

$\mathrm{m}=$ membrane or mixing

$0=$ outlet

$\mathrm{p}=$ permeate

$r=$ recycle

$\mathrm{s}=$ solute

$\mathrm{T}=$ tank

$\mathrm{w}=$ water

\section{REFERENCES}

Ahmad .A L, Chang M. F and Bhatia.S, 2007, Mathematical Modelling of Multiple Solutes Systems for Reverse Osmosis Process in Palm Mill Effluent, J. Chemical Engineering Vol 132, No1-3, 183-193.

Alatiqi, I. M, Ghabris, A. H and Ebrahim S, 1989, System Identification and Control of Reverse Osmosis Desalination, Desalination, 75(1-3), 119-140.

Assef, J. Z, J. C. Watters, P. B. Desphande and I. M. Alatiqi, 1995, Advanced Control of a Reverse Osmosis Desalination Unit. Proc.International Desalination Association (IDA) World Congress, Abu Dhabi, Vol. V, 174-188.

Chaaben A.B. and Ridha Andouls 2008, MIMO Modelling Approach for a Small Photovoltaic Reverse Osmosis Desalination System, Research unit RME,INSNT North Urban Centre, BP 676,1080,Tunis,Tunisia.

Fkirin,M A, and .Al Madhair, A F, 1997, Prediction of Time Varying Dynamic Processes, International Journal of Quality \& Reliability management, Vol 14, Issue 5, pp 505-511.

Gambier.A, Krasnik.A and Badreddin.E., 2007, Dynamic Modelling of a RO Desalination Plant for Advanced Control Purposes. American Control Conferences, Vol 7, Issue 9, pp 4854-4859.

K. Ogata, Discrete- Time Control Systems, Prentice Hall 1987, 994 pages

Purkait. M.K. and D. K, Maity, 2009, Treatment of Leather Plant Effluent using NF Followed by RO \& Permeate Flux Prediction using ANN, Chemical Engg .J. Vol 151, Issue 1-3, pp 275-85.

Ramaswamy S., P. B. Deshpande, S. S. Tambe and B. D. Kulkarni. 1995, Neural Networks for the Identification of MSF Desalination Plant, Desalination, Vol 101, Issue2, pp 185-193, 
Riverol, C., and V. Pilipovik, 2005, Mathematical Modeling of Perfect Decoupled Control System and its Application: A reverse osmosis desalination industrial-scale unit. Journal of Automated Methods and Management in Chemistry, Issue 2, pp50-54.

Robertson, M.W., J. C. Watters, P. B. Desphande, J. Z. Assef and I. M. Alatiqi, 1996, Model Based Control for Reverse Osmosis Desalination Processes. Desalination, 104, Issue 1-2, pp 59-68.

Saengrung, and Auncha 2005, Modeling of Reverse Osmosis Plants using System Identification \& Neutral Networks Journal of Master abstract International, Vol 41-03, pp 0856.

Senthil Murugan,R, and S.,Gupta Sharad, 2008, Modeling of a Radial Flow Hollow Fibre Module \& Estimation of Model Parameters for Aqueous Multi-Component Mixture using Numerical Techniques, journal of membrane science, Vol 279 No1-2, pp 466-478, Year 2006.

Sobana S and Rames C Panda, 2011, Identification, Modelling and Control of Continuous Reverse Osmosis Desalination System - A Review, Separation Science and Technology, 46,1-10.

Sobana S. and Rames C. Panda, 2013, Development of a Transient Model for the Desalination of Sea/Brackish Water through Reverse Osmosis, Desalination \& Water treatment Journal, 51(13-15), 2755-67..

Zilouchian A and Jafar M, 2001, Automation and Process Control for a Reverse Osmosis Plant using Soft Computing Methodology, Desalination, 135, 51-59.

\section{APPENDIX - 1}

$$
\begin{aligned}
& H=R O(x p) \\
& x p=A^{*} X X \\
& p p=A^{*} p^{*} A^{\prime}+Q \\
& k k=p p^{*} H^{*} i n v\left(H^{\prime} * p p^{*} H+R\right) \\
& x x=x p+k k^{\prime} *(\text { output }-h x(x p)) \\
& p=p p-k k^{*} H^{\prime} * p p
\end{aligned}
$$

Where

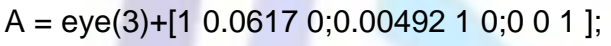

$$
\begin{aligned}
& \mathrm{Q}=\left[\begin{array}{lllllll}
0.01 & 0.01 & 0.01 ; 0.01 & 0.01 & 0.01 ; 0.01 & 0.01 & 0.01
\end{array}\right] \text {; } \\
& R=0.05 \text {; } \\
& \mathrm{H}=\left[\begin{array}{lllllll}
1 & 0 & 0 ; 0 & 1 & 0 ; 0 & 0 & 1
\end{array}\right] \text {; } \\
& \mathrm{XX}=\left[\begin{array}{lll}
1000 & 80 & 7.5
\end{array}\right]^{\prime} ; \%\left(3^{*} 1\right) \\
& P=10^{\star} \text { eye }(3) ; \% \operatorname{dia}(10)\left(3^{*} 3\right) \\
& x x 1=\text { Concentration of Permeate } \\
& x \times 2=\text { Flowrate of permeate }
\end{aligned}
$$

$\mathrm{x} \times 3=\mathrm{pH}$ of permeate

function $(z p)=h x(x h a t)$

$x x_{1}=\operatorname{xhat}(1)$

$x x_{2}=x h a t(2)$

$x x_{3}=x h a t(3)$

$z p=\sqrt{x x_{1}^{2}+x x_{2}^{2}+x x_{3}^{2}}$

function $(H)=R O(x p)$ 


$$
\begin{aligned}
& x x_{1}=x p(1) \\
& x x_{2}=x p(2) \\
& x x_{3}=x p(3) \\
& H(1)=x x_{1} / \sqrt{x x_{1}^{2}+x x_{2}^{2}+x x_{3}^{2}} \\
& H(2)=x x_{2} / \sqrt{x x_{1}^{2}+x x_{2}^{2}+x x_{3}^{2}} \\
& H(3)=x x_{3} / \sqrt{x x_{1}{ }^{2}+x x_{2}{ }^{2}+x x_{3}{ }^{2}}
\end{aligned}
$$

\begin{tabular}{|c|c|}
\hline & $\begin{array}{l}\text { Sobana Subramani obtained her BE in Instrumentation \& Control from Bharathiar } \\
\text { University, ME in Control \& Instrumentation from Anna University in 2003. She is } \\
\text { presently working as an Assistant professor (SI grade) in Easwari Engineering College, } \\
\text { Chennai and is pursuing her PhD in the area of process control. She has wide } \\
\text { exposure in the field of desalination and related controls. Her area of work is PID } \\
\text { controller with SISO \& MIMO structures. She has many good research publications in } \\
\text { reputed journals. }\end{array}$ \\
\hline & $\begin{array}{l}\text { Rames C. Panda received the M.Tech. and Ph.D. degrees in chemical engineering in } \\
1989 \text { and 1994, respectively, from the Indian Institute of Technology, Madras. In 1993, } \\
\text { he joined Chemical Engg. Dept. of CLRI, Council of Scientific \& Industrial Research, as } \\
\text { a scientist. He looks after industrial instrumentation and process control related works. } \\
\text { He has carried out research works at University of Karlsruhe (TH), Germany in 1997- } \\
8 ., \text { at PSE, Chem Engg Dept, NTU, Taiwan (2002-3) and Chem Engg Dept, Curtin Univ } \\
\text { of Tech, Australia (2006-7). Presently, he is working as a Principal scientist \& faculty at } \\
\text { Chem Engg Dept., CLRI. His research area includes autotuning, PID controllers and } \\
\text { analysis of control systems, process modeling, and simulation }\end{array}$ \\
\hline
\end{tabular}

\section{Bibliography:}

